\title{
Evaluation of new processes to achieve a high yield of carbon nanotubes by CVD method
}

\author{
Farshad Taleshi
}

\begin{abstract}
In this study, we describe the synthesis of carbon nanotubes (CNTs) by chemical vapor deposition at $500^{\circ} \mathrm{C}$ to $975^{\circ} \mathrm{C}$, over $\mathrm{CO}_{3} \mathrm{O}_{4} / \mathrm{MgO}$ catalyst. The size of $\mathrm{CO}_{3} \mathrm{O}_{4}$ nanoparticles is controlled by changing cobalt nitrate concentration in aqueous solution by impregnation method. The main object of this study is the synthesis of CNTs that started suddenly without any preheating of catalyst nanoparticles. The effect of sudden initiation and conventional preheating processes of catalyst nanoparticles on yield of CNTs was then described. The results suggest that this sudden initiation of synthesis process affects the carbon yield and morphology of CNTs.
\end{abstract}

Keywords: Carbon nanotubes, Catalyst nanoparticles, CVD method, Impregnation

\section{Background}

The unique and exemplary physical properties of carbon nanotubes (CNTs) have spurred interest in a wide range of applications including nanoelectronics, nanocomposites, and gas storage [1,2]. Different growth techniques exist to synthesis the CNTs, such as arc discharge and chemical vapor deposition (CVD). Large quantity, good quality, and high degree of control of the CNTs can be obtained by the catalytic CVD techniques [3]. Recently, scientific groups dealt with the mechanism of the formation of carbon nanotubes. The role of pretreatment $[4,5]$ and the size of catalyst nanoparticles have been particularly discussed [6,7]. The study shows that the yield of CNT preparation significantly depends on metal particles on supported catalysts. Increase of catalyst nanoparticle loading and good dispersion are useful ways to obtain a high yield of CNTs [8-10].

According to the above points, in this study, we describe the effect of the sudden insertion of catalyst nanoparticles into the CVD reactor to produce CNTs for the first time. The aim was to enhance CNT productivity and to control their diameters. The resulting CNTs were characterized by scanning electron microscopy (SEM) (Philips, MAG $15 \mathrm{kV}, \times 30,000$, SE detector microscope, (Philips Tecnai) FEI Co., Hillsboro, OR, USA) and

Correspondence: far.taleshi@gmail.com

Department of Applied Science, Qaemshahr Branch, Islamic Azad University, PO Box 163, Qaemshahr, Iran transmission electron microscopy (TEM) (CM10, 100 $k V$, Philips).

\section{Methods}

The MgO-supported $\mathrm{Co}_{3} \mathrm{O}_{4}$ catalyst nanoparticles $\left(\mathrm{Co}_{3} \mathrm{O}_{4} /\right.$ $\mathrm{MgO}$ ) was prepared by simple impregnation method. In the first step, $1 \mathrm{~g}$ of $\mathrm{MgO}$ powder was dispersed in $50 \mathrm{ml}$ of ethanol, sonicated for $30 \mathrm{~min}$, and stirred at $75^{\circ} \mathrm{C}$. The desired weight percent of $\mathrm{Co}\left(\mathrm{NO}_{3}\right)_{2} \cdot 6 \mathrm{H}_{2} \mathrm{O}$ was then dissolved in $25 \mathrm{ml}$ of ethanol and was then added dropwise $(0.5 \mathrm{ml} / \mathrm{min})$ to the above solution. After completion, the mixture was stirred for $1 \mathrm{~h}$ and dried at $120^{\circ} \mathrm{C}$ on a hot plate, and the sample was calcined in an oven under $550^{\circ} \mathrm{C}$ for $2 \mathrm{~h} . \mathrm{Co}_{3} \mathrm{O}_{4} / \mathrm{MgO}$ catalytic substrates were prepared in four different concentrations of $\mathrm{Co}_{3} \mathrm{O}_{4}(10,20,30$, and $40 \mathrm{wt} . \%)$.

CNTs were synthesized by the catalytic decomposition of acetylene at different temperatures $\left(500^{\circ} \mathrm{C}\right.$ to $\left.975^{\circ} \mathrm{C}\right)$ over $\mathrm{Co}_{3} \mathrm{O}_{4} / \mathrm{MgO}$ using CVD method under atmospheric pressure. Next, $50 \mathrm{mg}$ of catalyst powder was dispersed uniformly on a quartz boat. Two different procedures were used for this work. In the first method, the conventional method $[4,7,11]$, the catalyst was placed in the center of a quartz tube. The CVD furnace was heated to a desired temperature in the atmospheric pressure. Subsequently, argon was fed at a flow rate of 300 $\mathrm{sccm}$ for $15 \mathrm{~min}$. A mixture of acetylene $(15 \mathrm{sccm})$ and carrier gas $(150 \mathrm{sccm})$ was introduced into the quartz tube and maintained at the reaction temperature for 15

\section{实}


min before the furnace was cooled down to room temperature under Ar protection. In the second method (the focus of this work), while keeping constant Ar carrier gas flow at $150 \mathrm{sccm}$, temperature of the furnace was raised to a desired temperature for the growth of CNTs. The quartz boat (containing the catalyst powder) was then placed directly in the middle of the furnace as acetylene gas was flowing simultaneously (with a flow rate of $15 \mathrm{sccm}$ ), and synthesis process of CNTs started suddenly. The synthesis of CNTs was carried out by pyrolysis of the acetylene feed gas for $15 \mathrm{~min}$.

\section{Results and Discussion}

In order to investigate the effect of the catalyst's sudden initiation to the reaction zone of the CVD furnace on the growth of CNTs, carbon yield in two different mentioned methods was compared. The carbon yield was calculated using the following equation:

$$
\text { Carbon yield }=\left[\left(\mathrm{M}_{\text {Total }}-\mathrm{M}_{\mathrm{Cat}}\right) / \mathrm{M}_{\mathrm{Cat}}\right] \times 100 \%
$$

where $M_{\text {Total }}$ is the total mass of the final catalyst and carbon products and $M_{\mathrm{Cat}}$ is the initial mass of catalyst. The results of four different weight percentages of $\mathrm{Co}_{3} \mathrm{O}_{4}$ are shown in Figure 1. Comparing Figure 1a with Figure 1b, it can be seen that carbon yield in the second method (sudden initiation of catalyst) is considerably higher than the first one (conventional method). This is an important point that other researchers did not pay attention to. On the other hand, for temperatures higher than $800^{\circ} \mathrm{C}$ and contents more than 30 wt.\%, carbon yield decreases rapidly in the first method compared with that in the second one wherein higher carbon yield is achieved. This can be a result of thermal shock, caused by the sudden entrance of catalyst in the reaction zone with high temperature, which then crumbles the aggregated catalyst nanoparticles. This in fact increases the number of nanoparticles implied for CNT growth and the carbon yield, whereas in the first method, catalyst maintenance in that high temperature of furnace causes more aggregation of catalyst nanoparticles which then form bigger particles and therefore less carbon yield.

SEM (Figure 2) studies reveal that CNTs were produced over $\mathrm{Co}_{3} \mathrm{O}_{4} / \mathrm{MgO}$ (20 and 40 wt.\%) catalysts prepared under sudden initiation conditions cited above (magnification of all images is $1 \mu \mathrm{m}$ ). The existence of intertwined CNTs in Figure 2 indicates that $600^{\circ} \mathrm{C}$ is the appropriate temperature for the reduction of cobalt oxide nanoparticles, and the high catalyst activity for both weight percentages of catalyst (20 and $40 \mathrm{wt} . \%$ ) is high. However, we cannot see any tubular structure such as fibers with abnormal and large diameters. As a conclusion from this result, we can suggest a uniformity of distribution in size of the initial catalyst nanoparticles. Results show that a lower temperature corresponds to thinner and less accessible CNTs, while a high temperature is for thicker diameter CNTs and increased carbon impurities because of the increase in size of nanoparticles and faster reaction rate. The reduced amount of CNTs was attributable to the catalyst partial surface deactivation. These results are in accordance with those reported by other researchers $[12,13]$. In contradiction to reported literatures [8,14], efficient CNT production can be achieved when pretemperature procedure is not used. We believe that if we do not heat the nanoparticles before synthesis of CNTs, the production might improve by keeping $\mathrm{Co}_{3} \mathrm{O}_{4}$ nanoparticles active for nucleation. Using this process, a high percentage of catalysts resulted in CNTs with low diameters and high yield without any negative effects reducing the production rate, and this is what we were trying to achieve.

For more investigation, TEM analysis was used to observe the structure and diameter of CNTs. In Figure 3, the TEM image of nanotubes grown on 20 wt.\% of $\mathrm{Co}_{3} \mathrm{O}_{4}$ at $600^{\circ} \mathrm{C}$ is shown. Their quality is high, and they show smooth walls with low impurity and by-product content. Also, most of the products have hollow structures, and they are CNTs; there is no fiber in the TEM image. In the TEM image, the diameter distribution of
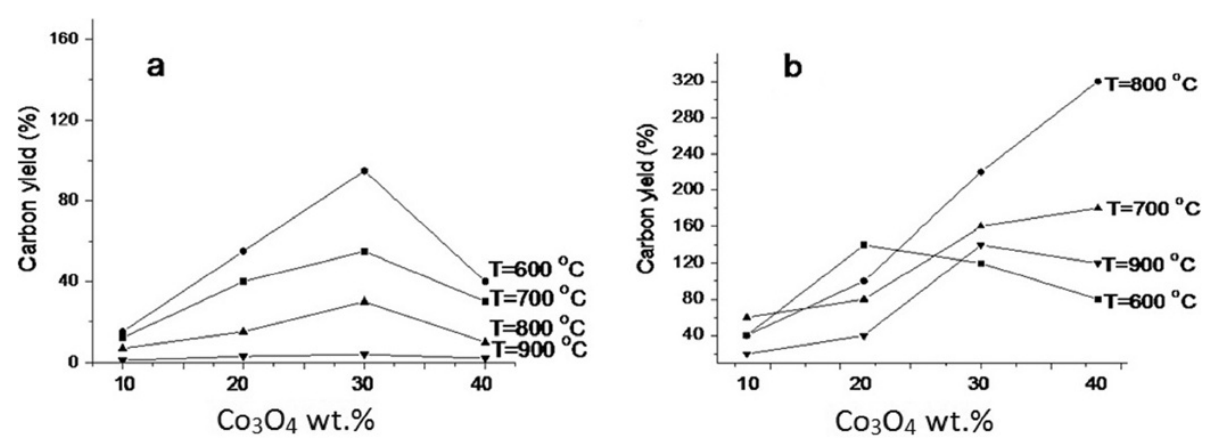

Figure 1 Carbon yield (\%) as a function of $\mathrm{Co}_{3} \mathrm{O}_{4}$ loadings (wt.\%) at different temperatures. (a) Synthesis of CNTs on calcined catalyst for 15 min (conventional method), and (b) the synthesis of CNTs that started suddenly. 

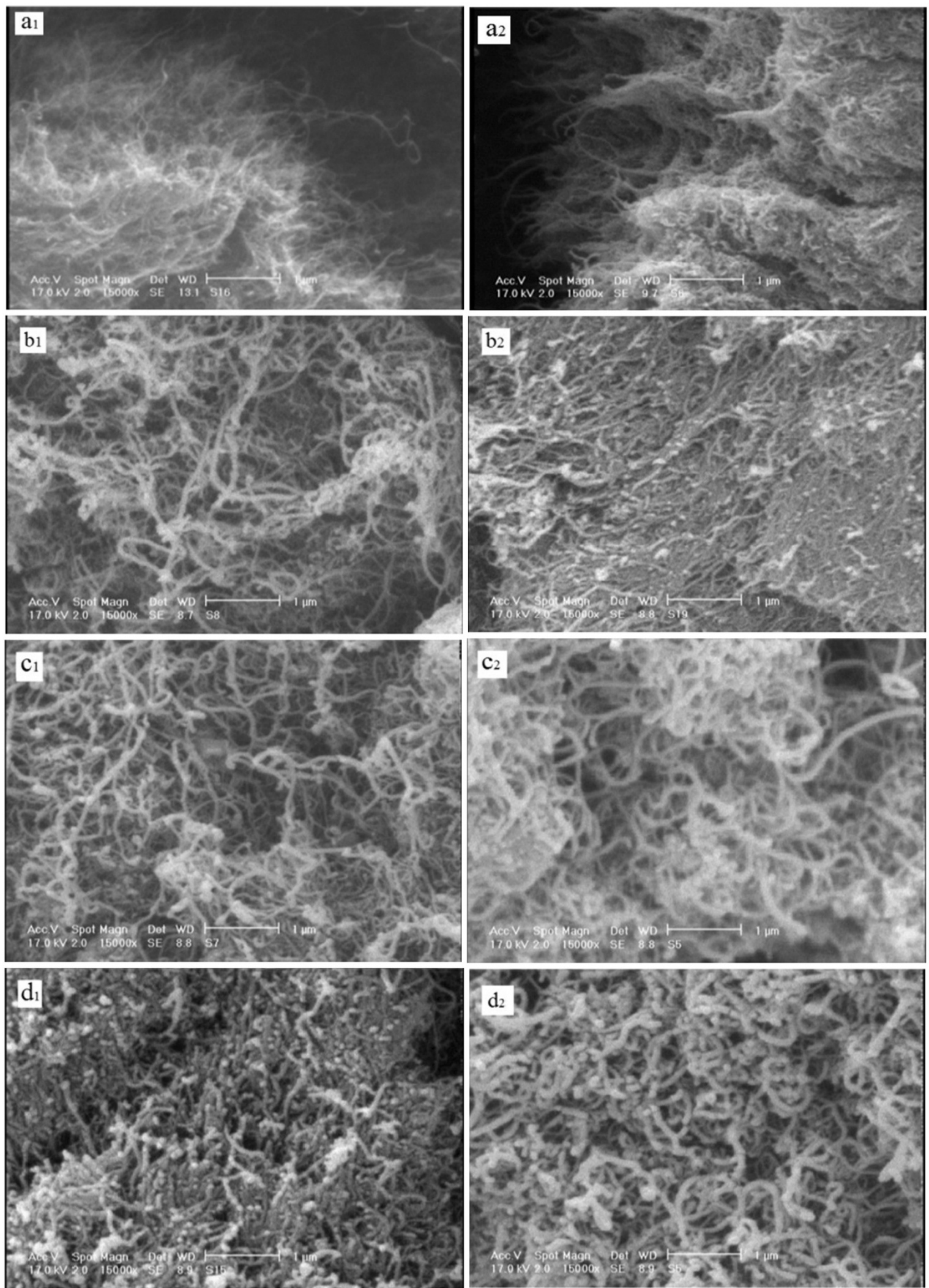

Figure 2 The SEM images of synthesized CNTs under sudden initiation conditions. At $600^{\circ} \mathrm{C}\left(\mathbf{a}_{1}, \mathbf{a}_{2}\right), 700^{\circ} \mathrm{C}\left(\mathbf{b}_{1}, \mathbf{b}_{2}\right), 800^{\circ} \mathrm{C}\left(\mathbf{c}_{1}, \mathbf{c}_{2}\right)$, and $900^{\circ} \mathrm{C}\left(\mathbf{d}_{\mathbf{1}}, \mathbf{d}_{\mathbf{2}}\right)$ with $\mathrm{C}_{2} \mathrm{H}_{2}$ Over $\mathrm{CO}_{3} \mathrm{O}_{4} / \mathrm{MgO}$ for $20 \mathrm{wt} . \%$ (indexed by 1 ) and $40 \mathrm{wt} . \%$ (indexed by 2). 


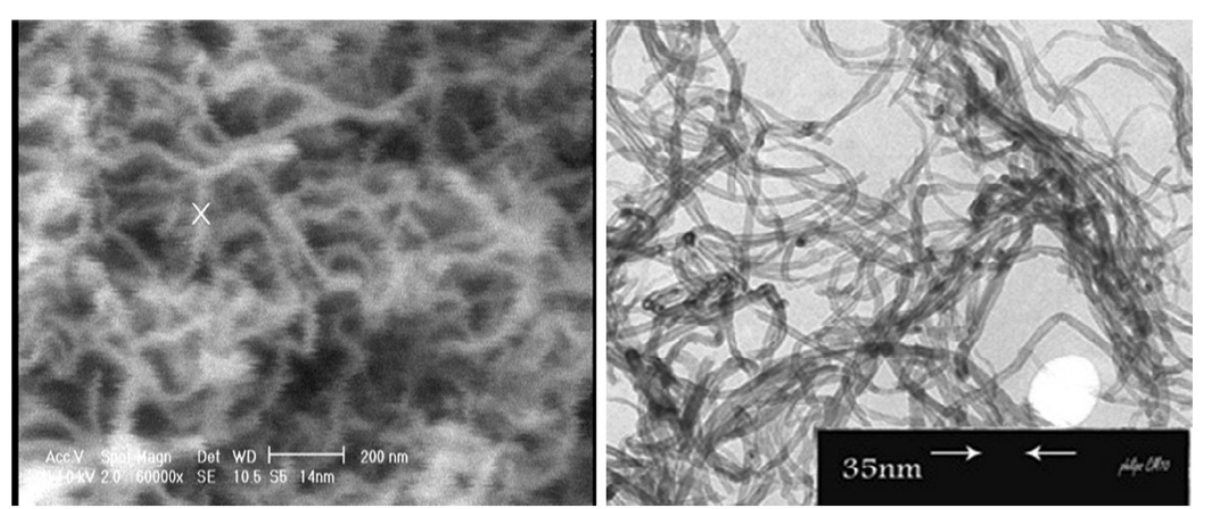

Figure 3 TEM image of synthesized CNTs at $600^{\circ} \mathrm{C}$ with $\mathrm{C}_{2} \mathrm{H}_{2}$ over $\mathrm{Co}_{3} \mathrm{O}_{4} / \mathrm{MgO}$ for 20 wt.\%.

produced CNTs is in the range of 10 to $22 \mathrm{~nm}$, and the average diameter is about $15 \mathrm{~nm}$.

Figure 4 shows the scattered temperature-diameter data between $600^{\circ} \mathrm{C}$ and $900^{\circ} \mathrm{C}$ with $\mathrm{C}_{2} \mathrm{H}_{2}$ over $\mathrm{Co}_{3} \mathrm{O}_{4} / \mathrm{MgO}$ for different weight percentages of $\mathrm{Co}_{3} \mathrm{O}_{4}$. A wide range of CNT diameters can be effectively synthesized over a range of temperatures. This scattered temperature-diameter data had shown a positive diameter-temperature relationship between $600^{\circ} \mathrm{C}$ and $900^{\circ} \mathrm{C}$. This happens because of the difference in the diffusion rate of catalyst nanoparticles into each other in different temperature ranges.

\section{Conclusions}

In this work, we used a novel strategy for the synthesis of CNTs with high carbon yield by a sudden initiation of catalyst in the CVD reactor that resulted from the rapid growth of CNTs taking place just before the new

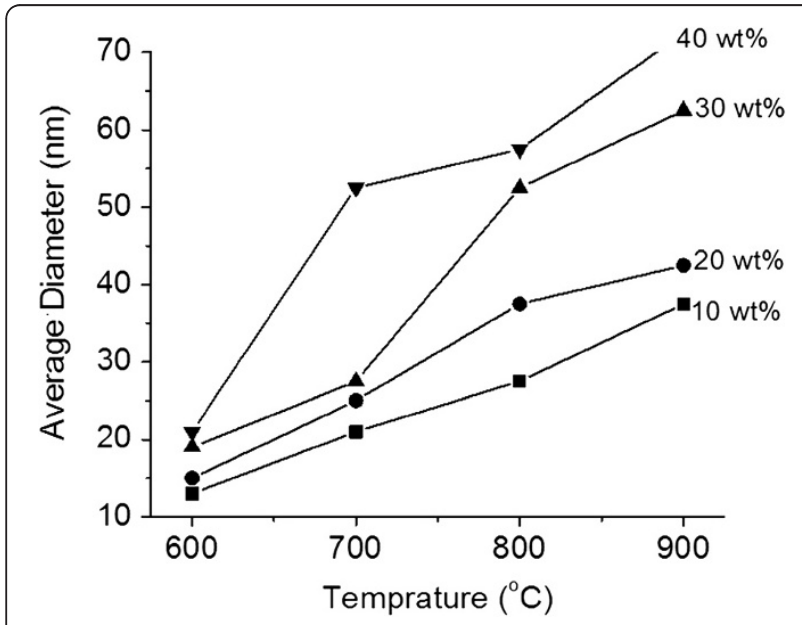

Figure 4 The scattered temperature-diameter data from $600^{\circ} \mathrm{C}$ to $900^{\circ} \mathrm{C}$ over $\mathrm{Co}_{3} \mathrm{O}_{\mathbf{4}} / \mathbf{M g O}$. This is for(a) 10 , (b) 20, (c) 30,and (d) 40 wt.\%. aggregation of crumbled catalyst nanoparticles under thermal shocking. However, we compare this new process with the conventional method for synthesis of CNTs.

\section{Competing interests}

The author declares that there are no competing interests.

\section{Acknowledgments}

The author would like to acknowledge the Qaem Shahr Branch of Islamic Azad University and the Iranian National Nanotechnology Initiation Council (INNIC) for their financial support to this project.

Received: 5 April 2012 Accepted: 25 September 2012 Published: 4 October 2012

\section{References}

1. lijima, S: Helical microtubules of graphitic carbon. Nature 354, 56 (1991)

2. Raffaelle, RP, Landi, BJ, Harris, JD, Bailey, SG, Hepp, AF: Carbon nanotubes for power applications. Materials Science and Engineering B 116, 233 (2005)

3. Dupuis, AC: The catalyst in the CCVD of carbon nanotubes-a review. Prog. Mater. Sci. 50, 929 (2005)

4. Terrado, E, Redrado, M, Munoz, E, Maser, WK, Benito, AM, Martinez, MT: Carbon nanotube growth on cobalt-sprayed substrates by thermal CVD. Mater. Sci. Eng. C 26, 1185 (2006)

5. Tran, KY, Heinrichs, B, Colomer, JF, Pirard, JP, Lambert, S: Carbon nanotube synthesis by the ethylene chemical catalytic vapour deposition (CCVD) process on $\mathrm{Fe}, \mathrm{Co}$, and $\mathrm{Fe}-\mathrm{Co} / \mathrm{Al}_{2} \mathrm{O}_{3}$ sol-gel catalysts. Appl. Catal. Gen. 318, 63 (2007)

6. Mac Kenzie, KJ, Dunens, OM, Harris, AT: An updated review of synthesis parameters and growth mechanisms for carbon nanotubes in fluidized beds. Ind Eng Chem Res 49, 5323 (2010)

7. Zhang, Q, Zhao, M, Huang, J, Qian, W, Wei, F: Selective synthesis of single/ double/multi-walled carbon nanotubes on $\mathrm{MgO}$-supported Fe catalyst. Chin. J. Catal. 29, 1138 (2008)

8. Li, H, Zhao, N, He, C, Shi, C, Du, X, Li, J: Catalytic synthesis of carbon nanostructures using $\mathrm{Fe}(\mathrm{OH})_{3} / \mathrm{Al}$ as catalyst precursors. J. Alloys Compd. 468,64 (2009)

9. Shajahan, M, Mo, YH, Fazle Kibria, AKM, Kim, MJ, Nahm, KS: High growth of SWNTs and MWNTs from $\mathrm{C}_{2} \mathrm{H}_{2}$ decomposition over Co-Mo/MgO catalysts. Carbon 42, 2245 (2004)

10. Tsoufis, T, Xidas, P, Jankovic, L, Gournis, D, Saranti, A, Bakas, T, Karakassides, MA: Catalytic production of carbon nanotubes over Fe-Ni bimetallic catalysts supported on MgO. Diamond Relat. Mater. 16, 155 (2007)

11. Kong, J, Cassell, AM, Dai, H: Chemical vapor deposition of methane for single-walled carbon nanotubes. Chem. Phys. Lett. 292, 567 (1998)

12. Makris, TD, Giorgi, L, Lisis, N, Salernitano, E: CNT growth on alumina supported nickel catalyst by thermal CVD. Diamond Relat. Mater. 14,815 (2005) 
13. Zhan, $S$, Tian, $Y, C$ Cui, $Y, W u, H$, Wang, $Y$, Ye, S, Chen, $Y$ : Effect of process conditions on the synthesis of carbon nanotubes by catalytic decomposition of methane. China Particuology 5, 213 (2007)

14. Piao, L, Li, Y, Chen, J, Chang, L, Lin, JYS: Methane decomposition to carbon nanotubes and hydrogen on an alumina supported nickel aerogel catalyst. Catal. Today 74, 145 (2002)

doi:10.1186/2228-5326-2-23

Cite this article as: Taleshi: Evaluation of new processes to achieve a high yield of carbon nanotubes by CVD method. International Nano Letters 2012 2:23.

Submit your manuscript to a SpringerOpen ${ }^{\circ}$ journal and benefit from:

- Convenient online submission

- Rigorous peer review

- Immediate publication on acceptance

- Open access: articles freely available online

- High visibility within the field

- Retaining the copyright to your article

Submit your next manuscript at $\gg$ springeropen.com 